\title{
THE NATURAL HISTORY OF THE WORKERLESS ANT PARASITE FORMICA TALBOTAE
}

\author{
BY MARY TALBOT
}

The Lindenwood Colleges, St. Charles, Missouri 63301 U.S.A.

Abstract: The ant Formica talbotae Wilson is a workerless social parasite of the microgyna group, which forms mixed colonies with the host ant Formica obscuripes Forel. Queens produce males and females only and there is also no worker brood of $F$. obscuripes in the parasitized colonies. The small alates have a long flight period stretching from mid-June to late September, with flights taking place on every suitable morning when the temperature is above $71^{\circ}$ and rising, when the sun is shining, and when there is no appreciable wind. Flights are best between $78^{\circ}$ and $83^{\circ} \mathrm{F}$. Once up on plants, alates are reluctant to return to the nest so some flights, under poor conditions, are long drawn out. Flights are sparse, usually only 10 to 75 alates taking off in a day. Sometimes there is a small swarming reaction, with females loitering on plants above the nest while males fly about until they find them and mate.

Formica talbotae Wilson is the only known workerless social parasite of the genus Formica (Wilson, 1977). The queens live in colonies of the thatching ant, Formica obscuripes Forel, and produce winged males and females all through the summer. Since all of the brood in such a colony is that of the parasite (a few $F$. obscuripes males may be produced and are probably the result of worker-laid eggs), it is assumed that the small fertilized females enter colonies which lack queens or in some unknown manner bring about the death of any queen which may be present.

E. O. Wilson (1977), who described $F$. talbotae, reports that this small member of the microgyna group has also been found at Spirit Lake, Iowa, by Robert L. King and near Grand Forks, North Dakota, by Paul B. Kannowski.

The $F$. talbotae colonies presented here were associated with five colonies of $F$. obscuripes on the Edwin S. George Reserve, Livingston County, Michigan. This is near the eastern margin for the distribution of the host ant, which is essentially a prairie form. F. obscuripes finds an excellent habitat on the Reserve since there are open, sloping fields which are sandy and well drained. Mounds are numerous in some fields, a condition necessary for the existence of such a parasite as $F$. talbotae. 
The parasites were first detected on June 25, 1969, when small males were seen coming from a nest of $F$. obscuripes near the end of the flying season of the latter species. In 1970 two more mixed colonies were located and all three were studied during the summer. By 1971 the two smaller colonies had disappeared, but the thriving one was watched until it was dug on August 16, 1971. By this date a fourth colony had been discovered, and it produced males and females until the end of the season but was not present in 1972. The fifth colony was found in July of 1974 and was still vigorous at the end of that year. During these years a great many nests of $F$. obscuripes were checked but no more parasitized colonies were recorded. Mixed colonies must be relatively short-lived since no worker pupae of either species were ever found. Thus a colony would become weak and depopulated as its $F$. obscuripes workers were killed during foraging or died of old age.

The first colony found ("cherry nest") was the smallest. Its mound was under the shading branches of a large choke cherry tree and was partly overgrown by trailing blackberry. This was an abnormally shaded location and the extensive overgrowth indicated a weak colony. The "cedar nest" was 25 yards away at the base of a red cedar tree. Its thatch was mostly dried cedar leaves and was almost flat. It was not overgrown and received good morning and evening sun. The "field nest" (the nest dug) was again 25 yards away and formed a rough triangle with the first two. It was the largest, had a good mound of thatch, and occupied a typical habitat. It lay in a high, sunny field of Canada bluegrass (Poa compressa L.) with numerous forbs, such as wild bergamot (Monarda fistulosa L.), daisy-fleabane (Erigeron strigosus Muhl.), orange hawkweed (Hieracium aurantiacum L.), yarrow (Achilles millefolium L.), mullein (Verbascum thapsus L.), and goldenrod (Solidago spp.). Grass circling the mound was tall; and it, together with a small shrubby elm, a bergamot, and a goldenrod plant, gave climbing support for flying ants and furnished flickering shade for the mound during early morning and late afternoon. The fourth colony was almost as small as the "cherry nest." It lay in a lower field about 160 yards from the first three and was almost completely overgrown with trailing blackberry. The fifth colony, 12 yards beyond in the same field, was almost as large as the colony dug. Thus all five colonies 
were in one part of the Reserve, and the only evidence that there might be more was the finding of an alate female a mile away.

Development of brood. Larvae and a few alate pupae were already present when observations began on June 3. Larvae were found all summer until August 16 and pupae until September 18. Adult alates were taken first on June 16, but they must have been in the nest slightly before this for the initial flight occurred on that date. The last flight seen was on September 20, but a few alates were still in the nest on October 1 when observations ceased. There was a steady production of alates all summer and brood was always abundant. Larvae and pupae were kept together in the lower parts of the central thatch or in soil chambers below or to the sides. No worker brood of either species was found.

Population count. On August 16, 1971, the largest colony was dug with the help of three friends, and an attempt was made to collect all the inhabitants. After the digging, thatch and soil were again sorted for possible overlooked brood, and for the next two weeks workers were captured along trails and outposts until there were no more. On the outside, the nest had a cone of thatch 9 inches high in the center and $17 \times 17$ inches in diameter. Around this a grassy ring made the total nest area $30 \times 30$ inches. Thatch extended down 17 inches beneath ground surface level. The first larvae and pupae were 10 to 14 inches down in the thatch, and more were located deeper in the thatch and in the soil beneath it to about 30 inches. Around the sides, more chambers with brood were present in the soil, beginning at 14 inches. No brood was below 30 inches, although at 35 inches there were still more galleries going down and ending blindly. All of the side chambers were in a diameter of 26 inches.

F. obscuripes workers totaled 4,620 , a fairly small population for this species. N. A. Weber (1935) counted 16,481 workers in a nest and said that this was not a complete count. R. L. King (1950) estimated over 50,000 workers in a large colony.

All ten dealate females of $F$. talbotae were in the central thatch and $87 \%$ of the winged males and females were there also. The nest contained 593 adult alates of which 263 were females and 330 were males. There were 1,127 pupae and 288 larvae, making a brood total of 1,415. Most of these were in chambers in the soil ( $78 \%$ of the pupae and $80 \%$ of the larvae). This distribution may have been influenced by the extremely dry condition of the thatch and upper soil. 
The 2,018 ants (adult plus brood) revealed in the digging in mid-August were only part of the production for the year since flights had been going on since June 16. If only 20 to 25 flew a day on a possible 30 to 35 favorable days, then 600 to 800 had already escaped, giving approximately 2,600 to 2,800 as the total estimated population. If $44 \%$ of these were females, then 1,100 to 1,200 females might have left this nest in 1971 if it had not been dug.

Flights. Since the ants had a long flying season, flights were not watched constantly. After the flight pattern was determined, they were checked at various times during the summer to determine that adult alates were being produced constantly and that flying took place on each day that weather permitted. Flying ants were seen to leave the nest on 48 days.

The "field nest" gave the earliest record for a flight (6-16-71). In 1970 it ran out of alates by September, but the "cherry" and "cedar" nests both had flights on September 20 and had a few males in the nest as late as October 1 . This gave a possible flying season of about 100 days. If two-thirds of these had proper weather for flying, there could have been 75 flight days in a season. This extended flight period is in marked contrast to that of the host species $F$. obscuripes, which has its flights within a period of approximately 30 days (during June), and in that time individual colonies may have 5 to 16 flights (Talbot, 1972).

Flights were tedious to watch because the small males and females were inconspicuous and because many flights were sparse and prolonged, with only a few ants coming up on plants at a time. Often there were only one to 16 alates on plants above the nest and from 10 to 15 males and from 6 to 12 females moving about on the mound. They were most abundant on the nest or on plants above when flying conditions were submarginal, and they were encouraged to come out but not to fly just before the temperature was high enough or when the sky darkened or temperature dropped. One peculiarity of the alates was their reluctance to return to the nest once they had climbed plants and were ready to fly. This sometimes lengthened flights and once, when conditions did not improve, 3 males were still hanging onto grasses at 4:30 p.m. Flying rate was often very slow. A mean of one ant flying a minute was usual and 3 or 4 a minute constituted a good flight. Sometimes 2 to 8 minutes elapsed between the takeoff of 2 ants. 
Since flights were generally sparse, the releasing of 75 alates constituted a good flight. Some were larger but some involved as few as 10 to 30 alates.

The longest flights occurred after a cold night when the temperature rose slowly because the day was hazy or when conditions were not quite ideal. One, watched continuously, lasted one hour and fifty minutes. On that day the temperature kept hovering between $70^{\circ}$ and $71^{\circ} \mathrm{F}$. Conversely, flights could be quite short. One lasted only 39 minutes because, after a heavy fog, the sun warmed rapidly to $85^{\circ}$ and flying stopped. In this time 10 males and 8 females flew and one mating was seen. Another flight was cut short in 13 minutes.

Flights began at varying times in the morning, depending on how cold the night had been and how quickly the mound and air warmed. The earliest flight seen began at $6: 30 \mathrm{a} . \mathrm{m}$. and the latest at 10:30 a.m. (E.S.T.). Males and females could come out on the mound when the temperature rose above $57^{\circ}$ and could begin to climb at $68^{\circ}$ to $70^{\circ}$. A few have been seen to fly at $69^{\circ}$ to $71^{\circ}$ but few flew before the temperature reached $72^{\circ}$ or above, and the best flying took place between $78^{\circ}$ and $82^{\circ}$. None was seen to fly above $85^{\circ}$. When mound surface reached $84^{\circ}$ to $85^{\circ}$, alates no longer came to the surface. (Unless otherwise stated, all temperatures were taken 10 inches above the ground, at about the height from which ants flew.)

Various other factors beside temperature determined time and length of flight. Rain, darkening sky, or swaying grasses could stop or prevent a flight. One stopped at 7:45 a.m. because of a strong wind and decreasing light, although temperatures were favorable. One lasted until 11:45 a.m. and finally dragged to a close when gathering clouds caused the air temperature to drop to $70^{\circ}$. When conditions were submarginal, it was sometimes hard to tell when flight ended because a few alates would stay on the nest; and occasionally, at long intervals, one would climb and fly. Such a flight could last into the afternoon.

One day males and females came out of the mound at $64^{\circ}$ to $66^{\circ}$ but did not climb because, although the temperature reached $72^{\circ}$, it fluctuated between this and $62^{\circ}$, going up and down rapidly with passing clouds. On another day the "cedar nest" had a flight but the other two did not, for different reasons. At the "cherry nest" shade kept the temperature too low. "Field nest" alates 
in the sun had adequate warmth, but a wind kept the plants in almost constant motion. Ants at the "cedar nest" could fly because they were in the sun and because they could climb the cedar trunk to take off, thus avoiding moving plants.

Both males and females could fly from grasses, but females often preferred the more stabile stalks of monarda or goldenrod. Sometimes they climbed rapidly with wings half spread and flew immediately. More often they came up slowly, stopping several times before reaching a plant tip from which they would fly after a brief fluttering of wings.

Females tended to loiter for a longer time than did males and so set up conditions for swarming on a miniature scale. Swarming was considered to exist when males, instead of flying off, flew among the plants, lighting on one stem after another, until they found females with which to mate. This did not take place on all flights. One typical swarm occurred on August 25, 1970, at $78^{\circ}$. When first seen, 10 females were standing on plants and 8 males were flying among them. One male united with a female and then moved off fluttering its wings; 3 others walked rapidly, with a jerking motion, among stems. One found a female and mated for a half minute. Then 2 others were seen mating. Other males and females joined the group. Males flew up and down among the plants, then lit on stems to find females. When females were in excess, they seemed to be waiting until males found them. This was a very low grade swarm but, aside from numbers involved and the fact that it took place over the nest, it was essentially like the ground swarms of $F$. obscuripes, which have been reported from the Reserve (Talbot, 1972), and still more like the small swarms which took place over the nest of Formica dakotensis Emery (Talbot, 1971).

\section{Literature Cited}

King, R. L. AND F. WAL.TERS

1950. Population of a colony of Formica rufa melanotica Emery. Iowa Academy of Science 57: 469-473.

TALвот, M.

1959. Flight activities of two species of ants of the genus Formica. The American Midland Naturalist 61: 124-132.

1971. Flights of the ant Formica dakotensis Emery. Psyche 78: 169-179.

1972. Flights and swarms of the ant Formica obscuripes Forel. J. Kansas Entomol. Soc. 45: 254-258. 
Weber, N. A.

1935. The biology of the thatching ant, Formica rufa obscuripes Forel, in North Dakota. Ecol. Monogr. 5: 165-206.

WilsoN, E. O.

1977. The first workerless parasite in the ant genus Formica. Psyche 83: 277-281. 


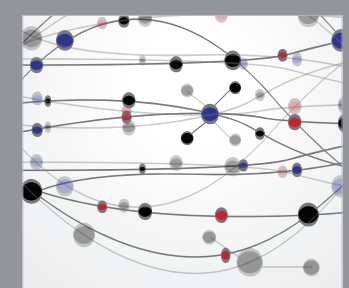

The Scientific World Journal
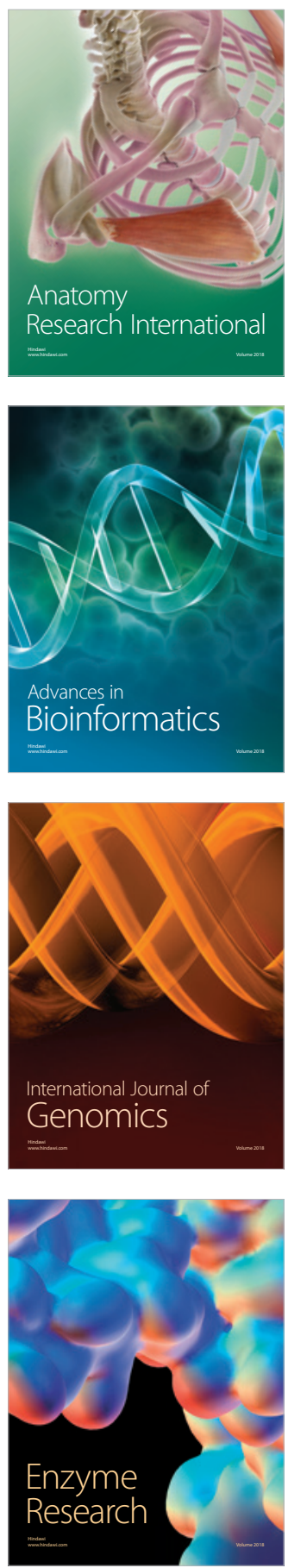
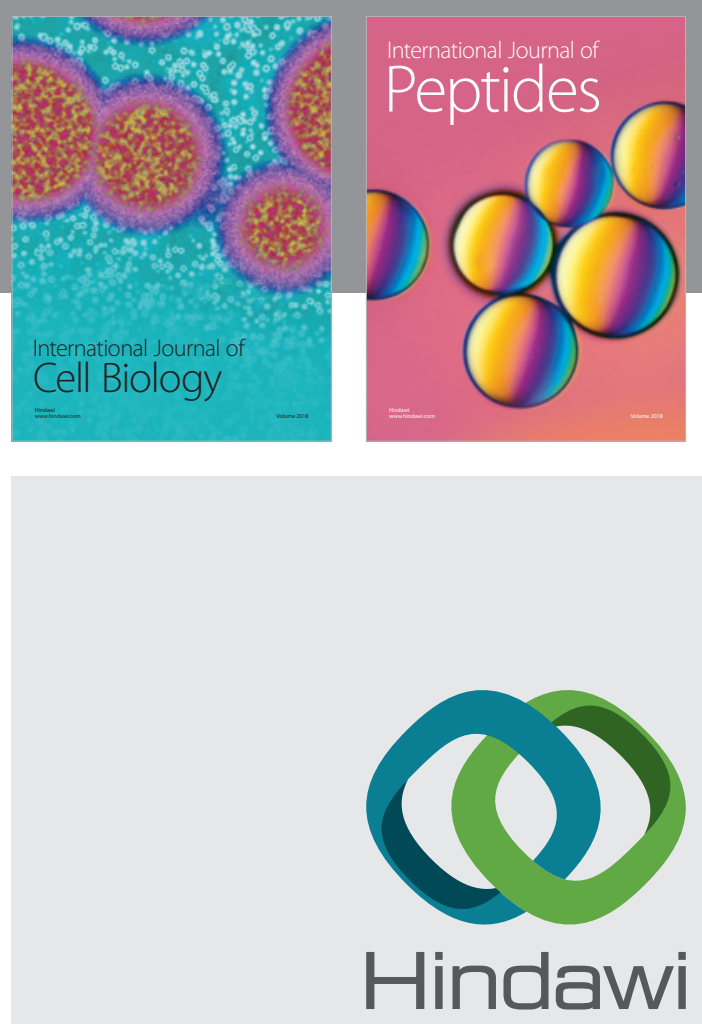

Submit your manuscripts at

www.hindawi.com
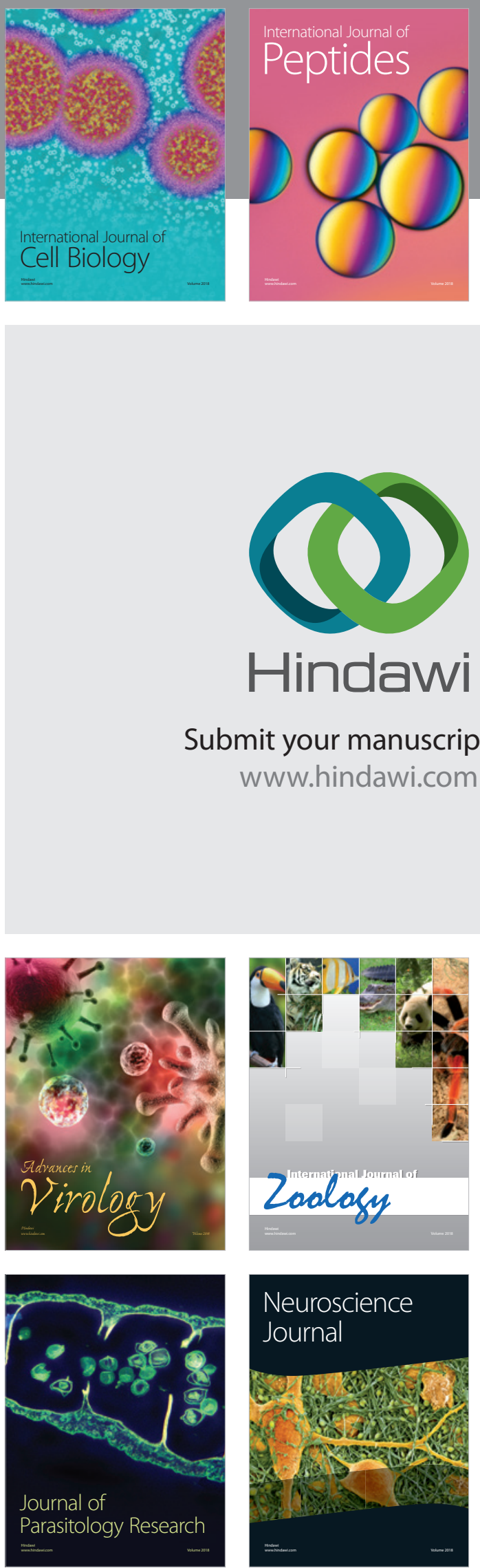
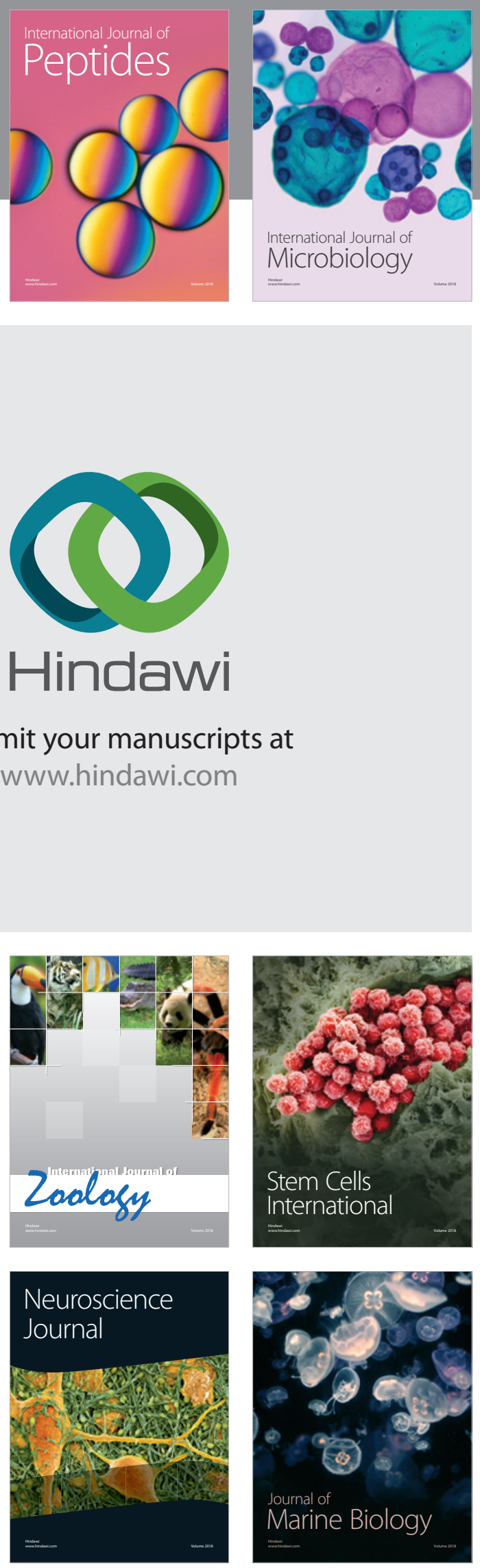
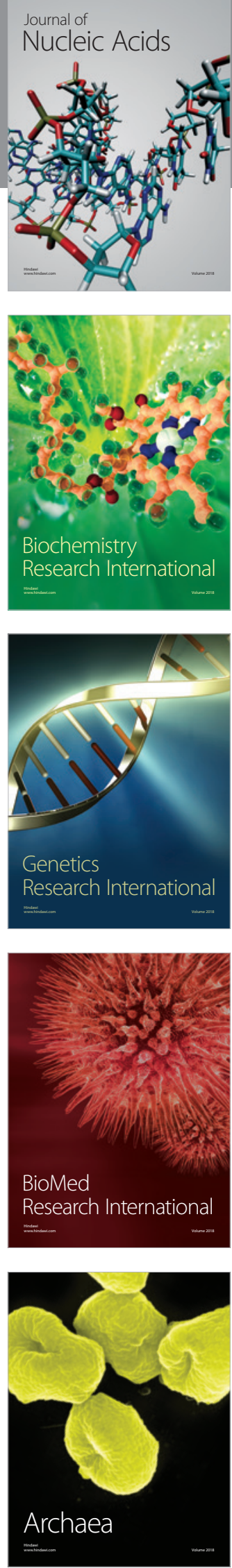